\title{
3 Research Square \\ Does trans fatty acid affect low birth weight? A randomized controlled trial
}

\section{Parvin Mirmiran}

Shaheed Beheshti University of Medical Sciences

Masoumeh Simbar

Shaheed Beheshti University of Medical Sciences

\section{Parvaneh Mirabi}

Babol University of Medical Science

\section{Golaleh Asghari}

Shaheed Beheshti University of Medical Sciences

Seideh Hanieh Alamolhoda ( $\square$ feri_mira@yahoo.com )

Shaheed Beheshti University of Medical Sciences

\section{Research article}

Keywords: Trans fatty acid, pregnancy, low birth weight, dietary pattern, prenatal care, maternal nutrition

Posted Date: September 1st, 2020

DOI: https://doi.org/10.21203/rs.3.rs-61709/v1

License: (c) (1) This work is licensed under a Creative Commons Attribution 4.0 International License. Read Full License 


\section{Abstract}

Objective: To evaluate the effect of low trans fatty acids (TFAs) dietary pattern during pregnancy on risk of low birth weight (LBW).

Methods: All pregnant women who received prenatal care with gestational age $<8$ weeks and aged $\leq 35$ years were included in this randomized controlled trial study that took place in Tehran from December 2014 to August 2016. Women in the intervention group received individualized dietary pattern with TFAs content of $<1 \%$; those in control group had dietary intake with no change on TFAs content. Dietary intakes were assessed by 3 non-consecutive 24-hour recalls at first prenatal care visit and at gestation age 13, 25 and 35 week. Hazard ratio was calculated using Cox proportional-hazards models. Incidence and hazard ratio $(95 \% \mathrm{Cl})$ for low birth weight based on multivariable adjusted models were calculated.

Result: Of the 800 women ( $n=407$ in control and $n=393$ in intervention groups), 108 (13.5\%) women were diagnosed with low birth weight. The incidence of LBW in intervention group was $12 \%$ and in control group was $19 \%$. After multivariable adjustment for confounders, the hazard ratios for incident low birth weight in intervention group were 0.65 (0.44-0.96). Kaplan-Meier plot showed significant difference between two groups in incidence of LBW.

Conclusion: Intake of low TFAs dietary pattern during pregnancy reduced risk of LBW.

Trial registration The trial has been registered in the Iranian Registry of Clinical.

Registration number: IRCT2016092729902N3. Registered 8 November 2016, https://en.irct.ir/trial/23919

\section{Background}

Low birth weight (LBW) (under 2500 grams) is an important public health problem that more than 20 million infants worldwide, representing 15.5 percent of all births, are born with LBW. Low birth weight is an adverse pregnancy outcome that it associated with baby's future health (1) and increased risk of perinatal mortality and childhood cognitive function disorder and adult chronic disorder such as cardiovascular disease and metabolic disorder $(2,3)$. The world health organization recommendation is to "decrease LBW (to) fewer than 30\% till 2025". (4).

Recently, some studies have shown the role of potential risk factors in pathogenesis of LBW such as hypertension, weight gain during pregnancy, pre-pregnancy weight, history of LBW and pre- and during pregnancy nutrition status (5-7). The maternal dietary intake may be an important element for fetal growth; some macro- and micro-nutrients have direct effect on LBW and others have adverse effect $(6,7)$. There is also no nutritional strategy to prevent LBW (7).

Nowadays, due to increased consumption of trans fatty acids (TFAs), intake of this group of fats and its impact on the health of individuals, especially pregnant women has been considered (8). The nutrition transition worldwide is taking place in the context of rapid life styles change, urbanization and social 
development which causes malnutrition and micronutrient deficiencies that those still dominate the public health nutrition agenda (9). During the nutrition transition, people consume more fast foods, bakery products, and high fat dairy products that are main sources in TFAs (10). Some cohort and casecontrol studies found adverse potential of TFAs on LBW (12-18). To best of our knowledge, no study has been conducted to investigate the effect of daily TFAs intake on LBW. Therefore, the aim of this randomized controlled trial was to examine the effect of low TFA dietary pattern on the development of LBW.

\section{Methods}

\section{Study design}

All patients provided written informed consent before participating in this randomized, 2-group parallel, controlled trial, which was approved by the Research Ethics Committee of the Research Institute for Endocrine Sciences of Shahid Beheshti University of Medical Sciences (IR.SBMU.ries.Rec.1394.92).

The study took place in Tehran from December 2016 to August 2018. We enrolled pregnant women from 8 health centers and randomly divided to intervention group with low TFAs daily intake during pregnancy and control group without any change in TFAs daily intake.

\section{Recruitment}

In the run-in phase of the study midwifes present at health centers 5 days in a week. The investigators informed the participant of all aspects pertaining to participation in the study and was screened all the patients for the eligibility criteria at the time of admission. Women's screening continued until the target population is achieved.

\section{Study population}

We assessed the eligibility of pregnant women attend to public health centers. Pregnant women who had a gestational age less than 8 weeks, singleton pregnancy and intention to receive prenatal care, $24>\mathrm{BMl}$ $>18$ pre pregnancy, $18 \leq$ age $\leq 35 y$ ears, gravid under 4 , abortion under or equal 2 were included. We excluded participants who had any previous history of chronic disease such as diabetes mellitus, any history of preeclampsia or gestational diabetes, any history of pre pregnancy hypertension and those who smoked or drank alcohol. The research coordinator described the study for pregnant women. Pregnant women were given suitable time to reflect on the information and their questions were answered and gave free and voluntary consent. A total of 1016 pregnant women were screened for eligibility. Among them 45 pregnant women not meeting inclusion criteria, 31 declined to participate and 28 participants for other reasons excluded from this trial. After these exclusions, 912 pregnant women were randomized in two group (intervention group $=455$, control group $=457$ ). Finally 800 pregnant women remained for the analysis (Fig. 1).

\section{Randomization}


This study was a randomized parallel dietary interventional study with a 1:1 allocation. Pregnant women were randomly allocated to one of two either group (low TFAs group and control group) in a $2 \times 4$ Latin Square design. Randomization was performed by person from health centers not involved in the study. The randomization table was kept in a locked file cabinet and in a password-protected computer in the midwifery group center.

\section{Blinding}

The outcomes assessor performing and analyzing data was blinded to the participant grouping.

\section{Obstetric management}

Women in both groups received routine prenatal care. Anthropometric measurements were performed with light clothing and without shoes. Weight and height were measured at the first visit in pregnancy (less than 8 weeks) according to the standard protocol. Pre pregnancy body mass index (BMI) was calculated by dividing the weight in kilograms by the square of height in meters on the basis of weights in pre pregnancy. Gestational age was ascertained by first day of last menstrual period and by ultrasound under 12 weeks of gestational age. Pregnant women had monthly obstetric visits up to 28 weeks of gestational age, biweekly visits from week 28 to week 36, and weekly visits until the end of the pregnancy. For both groups, prenatal data were obtained from the patients' medical records.

\section{Data collection and assessment}

Data was collected by face to face interview and using the structured questionnaire. The questionnaire had two parts. The first part of it was included to socio demographic background: maternal age, maternal education, and maternal occupation. The information of this part was important, because it showed the socioeconomic condition of participants that these could effect on the child birth weight. The second part of questionnaire obtained maternal condition such as gestational age, number of pregnancy, prenatal care follow up, gestational age at the first care, and pre pregnancy body mass index. The information about dietary intake was collected by dietary food recall in three days (one holiday and two week days).

All interviews and data collections were conducted by trained nutritionists based in health care centers. They were given 3 days training on interview technique and nutrition data collection. 5 nutritionists and 1 midwife supervised study.

\section{Study intervention}

Participants assigned to one of the two groups, the intervention ( $n=393)$ and the control $(n=407)$ group (Fig. 1). For all pregnant women individual dietary pattern were designed based on age, height, prepregnancy weight and physical activity. Indeed, Women in intervention group received individualized dietary pattern with TFA content under $1 \%$ of total daily energy intake, and in the control group, women received individualized dietary pattern without any focus on TFA content. In the intervention group, we replaced mono- and polyunsaturated fatty acids free of trans fatty acids in dietary pattern, such as olive oil, fish, nuts, and low fat (1.5\%) dairy products, and participants were forbidden to consume the food rich of trans fatty acids such as any kind of fast foods, processed meat, and deep fried foods; but in the 
control group, women were allowed to consume any kind of dairy products and oil for cooking and routine dietary recommendation were advised. For dietary assessment and ensure compliance, we used 24_hours dietary recalls (24h_DRs). For women dietary assessment, expert nutritionists assessed dietary intake of the participants using three non - consecutive 24-hour recalls, one weekend day (Thursday or Friday) and 2 weekdays. The personal interview has held in private and took about 20 minute. Portion sizes of meals are converted to grams by using household measures (19). Nutrient intakes are calculated according to the US Department of Agriculture and Iranian Food Composition Tables $(20,21)$. First recall interviews were performed at health center; second and third recalls were filled by call. The 24h_DR data were also collected at first prenatal care visit and the end of every trimester (13, 25, 35 weeks).All recalls were checked by investigators, and ambiguities were resolved with the women. Because the only available Iranian food composition table (FCT) analyzes a very limited number of raw food items and nutrients, we used the united states drug and food composition table (USDA FCT) as the main FCT; the Iranian FCT was used as an alternative for traditional Iranian food items, like kashk, which are not included in the USDA FCT. All pregnant women who participated in the study routinely received $1 \mathrm{mg}$ folic acid daily in the first trimester (up12 week) of and received multivitamin minerals daily from the beginning of the second trimester to the end of pregnancy. From the beginning of the 16th week of the pregnancy, all participants received the $30 \mathrm{mg}$ daily iron supplement.

Unannounced telephone calls were used both to encourage participants and to ascertain adherence to the dietary.

\section{Primary research question}

What is the effect of low trans fatty acids dietary pattern on the risk of LBW?

The primary endpoint was the rate of low birth weight, defined as those weighted were less than 2500 gram.

\section{Outcome measurement}

The weight of newborns was measured 60 minute after birth with a Seca scale. The scale was always checked and zeroed before weighting each child. Low birth weight newborns were those weighted under 2500 gram. All deliveries were conducted in a central hospital.

\section{Obstetric management}

Women in both groups received routine prenatal care. The participant's BMI was calculated on the basis of pre pregnancy weights (maximum three months before pregnancy) and heights at the first prenatal care visit (under 8 weeks of gestation). Gestational age was calculated by first day of last menstrual period or by ultrasound less than 12 weeks of gestational age. They had monthly obstetric visits up to 28 week of gestational age, every two weeks visits from week 28 to 36 week, and weekly visits until the end of the pregnancy. For both groups, antenatal and perinatal data were obtained from the patients' medical records.

\section{Statistical analysis}


We calculated sample size based on $\alpha=0.05,1-\beta=0.80$, and using the following formula:

$$
n=\frac{\left\{Z_{1-\frac{\alpha}{2}} \sqrt{2 \bar{P}(1-\bar{P})}+Z_{1-\beta} \sqrt{P_{1}\left(1-P_{1}\right)+P_{2}\left(1-P_{2}\right)}\right\}^{2}}{\left(P_{1}-P_{2}\right)^{2}}
$$

Accordingly, sample size in each group was 325 people, with the probability of miss to follow-up of $20 \%$, yielded to 400 persons per group.

Quantitative data were expressed as mean \pm standard deviation (SD), where applicable and quantitative data were presented as percentages. Independent sample T-tests and Chi-2 were used to compare variables among two groups, respectively. All conflicted variables were matched in both groups. Each variable's normality was checked by a histogram chart and one-sample Kolmogorov-Smirnov test. Repeated measure was used for analysis of nutritional and obstetrical changes during follow-up. When performing the Cox proportional-hazards model, groups were considered as independent variables and LBW as a dependent variable. Cox regression analysis is basically done when participants are followed up over time. In this case the exposure (independent variable) is the intervention of low TFA diet and the outcome is the birth weight that followed up during pregnancy. Incident rates and hazard ratios (95\% confidence interval) for LBW based on groups were calculated (Table 4). The potential confounders for each group were age, pre pregnancy BMI, gravid in the adjusted model. In this study we used the KaplanMeier plot, is a non-parametric statistic used to estimate the survival function from lifetime data. In medical research, it is often used to measure the fraction of patients living for a certain amount of time after treatment. In this study, the percentage difference in weight of newborns in two groups (intervention and control group) after the pregnant women intake diet was evaluated. All statistical tests were two sided, and a significant association was declared at P-value $<0.05$ (95\% confidence interval). All statistical analyses were performed using statistical package for social science (version 21; SPSS Inc., Chicago, IL, USA).

Table 4

Hazard ratio $(95 \% \mathrm{Cl})$ for developing LBW based on dietary pattern $\leq 1 \%$ TFAs intake

\begin{tabular}{|llll|}
\hline Models & Hazard ratios & Cl (95\%) & p-value \\
\hline Unadjusted Model & 0.65 & $0.44-0.96$ & 0.03 \\
Multi variables Model ${ }^{\star}$ & 0.64 & $0.44-0.95$ & 0.02 \\
\hline *: groups, age, pre pregnancy BMl, gravid were adjusted \\
\hline
\end{tabular}

Result 


\section{Flow diagram}

Among 1016 eligible women, 73 did not meet inclusion criteria, 31 refused consent, and 912 were consented and randomized, however a total of 800 pregnant women were remained for the final analysis (Fig. 1). The mean \pm SD age and pre pregnancy BMI for participants was $24.5 \pm 2.8$ years and $21.9 \pm 1.6$ $\mathrm{Kg} / \mathrm{m} 2$, respectively. There were no significant differences between two groups in age and pre pregnancy $\mathrm{BMI}(\mathrm{p}>0.05)$. 540 pregnant women (67.5\%) attended high school and 538(67.3\%) of them were housewives. Also, 601(75.1\%) of participants were nulliparous. According to Table 1, the baseline characteristics between control and intervention group was no different significantly.

Table 1

Baseline characteristics of the all participants and by intervention and control group

\begin{tabular}{|c|c|c|c|c|}
\hline \multirow[t]{2}{*}{ Variables } & $\begin{array}{l}\text { All } \\
(n=800)\end{array}$ & $\begin{array}{l}\text { Carob } \\
(n=407)\end{array}$ & $\begin{array}{l}\text { Vitamin E } \\
(n=393)\end{array}$ & P-value® \\
\hline & Mean \pm SD & Mean \pm SD & Mean \pm SD & \\
\hline Age ( year) & $24.5 \pm 2.8$ & $24.6 \pm 2.7$ & $24.4 \pm 2.9$ & 0.31 \\
\hline Pre pregnancy BMI (kg/m²) & $21.9 \pm 1.61$ & $21.9 \pm 1.63$ & $22 \pm 1.72$ & 0.34 \\
\hline Ge Gestational age at delivery time(year) & $38 \pm 3$ & $38 \pm 2$ & $38 \pm 4$ & 0.56 \\
\hline blood pressure $<7$ weeks & $109.7 \pm 7.33$ & $109 \pm 7.36$ & $109.7 \pm 7.67$ & 0.93 \\
\hline \multirow[t]{2}{*}{ House wives occupation } & $\mathrm{n}(\%)$ & $\mathrm{n}(\%)$ & n (\%) & 0.82 \\
\hline & $538(67)$ & $266(66)$ & $272(68)$ & \\
\hline High school education & $540(67)$ & $272(68)$ & $268(67)$ & 0.11 \\
\hline Nulliparous & $601(75)$ & $302(74)$ & $299(76)$ & 0.12 \\
\hline Para 0 & $667(83)$ & $347(83)$ & $330(83)$ & 0.56 \\
\hline Abortion 0 & $714(89.3)$ & $352(89)$ & $362(89)$ & 0.23 \\
\hline
\end{tabular}

A comparison of dietary intake at baseline and end of every trimester between the control and intervention groups revealed that there was no significant difference in daily intake of energy, carbohydrate, protein and total fat between the two groups $(p>0.05)$. However, there were significant differences in intake of daily MUFA (in25 and 35 weeks) and TFAs(13, 25 and 35 weeks) in both groups $(p<0.05)$. In intervention group, all women's consumed TFAs less than $1 \%$ of daily energy intake. (Table 2). 
Table 2

Dietary intake of participants according to intervention and control group

\begin{tabular}{|c|c|c|c|c|}
\hline & & $\begin{array}{l}\text { Control } \\
(n=407)\end{array}$ & $\begin{array}{l}\text { Intervention } \\
(n=393)\end{array}$ & $P$-value \\
\hline \multirow[t]{4}{*}{ Energy (kcal) } & $<7$ weeks & $2083 \pm 241$ & $2024 \pm 207$ & 0.06 \\
\hline & 13weeks & $2024 \pm 61$ & $2015 \pm 54$ & 0.08 \\
\hline & 25weeks & $2352 \pm 53$ & $2346 \pm 53$ & 0.06 \\
\hline & 35weeks & $2457 \pm 50$ & $2447 \pm 52$ & 0.07 \\
\hline \multirow[t]{4}{*}{ Carbohydrate (\%) } & $<7$ weeks & $50 \pm 3.81$ & $51 \pm 3.21$ & 0.06 \\
\hline & 13weeks & $53 \pm 3.32$ & $55 \pm 2.55$ & 0.07 \\
\hline & 25 weeks & $52 \pm 3.13$ & $53 \pm 2.52$ & 0.06 \\
\hline & 35 weeks & $53 \pm 3$ & $54 \pm 2.62$ & 0.07 \\
\hline \multirow[t]{4}{*}{ Protein (\%) } & $<7$ weeks & $13 \pm 1.41$ & $12 \pm 1.36$ & 0.06 \\
\hline & 13weeks & $18 \pm 1.24$ & $19 \pm 1.25$ & 0.08 \\
\hline & 25weeks & $17 \pm 1.23$ & $18 \pm 1.26$ & 0.07 \\
\hline & 35 weeks & $17 \pm 1.11$ & $18 \pm 1.02$ & 0.07 \\
\hline \multirow[t]{4}{*}{ Total fat (\%) } & $<7$ weeks & $37 \pm 10$ & $37 \pm 8$ & 0.06 \\
\hline & 13weeks & $30 \pm 6.65$ & $30 \pm 6.23$ & 0.08 \\
\hline & 25weeks & $31 \pm 3.12$ & $30 \pm 3.24$ & 0.08 \\
\hline & 35 weeks & $30 \pm 2.61$ & $29 \pm 2.94$ & 0.07 \\
\hline \multirow[t]{4}{*}{ TFAs (\%) } & $<7$ weeks & $10 \pm 2.32$ & $9 \pm 1.34$ & 0.07 \\
\hline & 13weeks & $8 \pm 1.33$ & $1 \pm 0.82$ & 0.04 \\
\hline & 25weeks & $7 \pm 1.15$ & $0.91 \pm 0.65$ & 0.03 \\
\hline & 35 weeks & $7 \pm 1.45$ & $0.89 \pm 0.60$ & 0.03 \\
\hline
\end{tabular}




\begin{tabular}{|c|c|c|c|c|}
\hline & & $\begin{array}{l}\text { Control } \\
(n=407)\end{array}$ & $\begin{array}{l}\text { Intervention } \\
(n=393)\end{array}$ & $P$-value \\
\hline Poly unsaturated fatty acids & $<7$ weeks & $15 \pm 4.56$ & $16 \pm 6.76$ & 0.09 \\
\hline \multirow[t]{7}{*}{ Mono unsaturated fatty acids } & 13weeks & $10 \pm 4.32$ & $10 \pm 4.21$ & 0.08 \\
\hline & 25weeks & $10 \pm 3.76$ & $10 \pm 4.12$ & 0.07 \\
\hline & 35weeks & $10 \pm 2.25$ & $10 \pm 3.13$ & 0.08 \\
\hline & $<7$ weeks & $12 \pm 3.34$ & $12 \pm 3.31$ & 0.09 \\
\hline & 13weeks & $12 \pm 2.43$ & $11 \pm 3.65$ & 0.08 \\
\hline & 25weeks & $14 \pm 2.31$ & $19 \pm 1.34$ & 0.03 \\
\hline & 35weeks & $13 \pm 3.13$ & $18 \pm 1.04$ & 0.03 \\
\hline
\end{tabular}

Of the 800 participants, 101 (13.5\%) child was born with weight under 2500 gram. The incidence rate of LBW was $12 \%$ for women who had dietary pattern with TFAs content $<1 \%$ (intervention group) and $19 \%$ for women who did not have any change in TFAs content in their diet (control group). Chi-square test showed a significant difference between two groups in terms of low birth weight (Table 3). Unadjusted hazard ratios $(95 \% \mathrm{Cl})$ for LBW were $0.65(0.44-0.96)$. However, after adjustment for confounders, the corresponding hazard ratios attenuated to $0.64(0.44-0.95)$ in multi variables model (Table 4).

Table 3

Frequency distribution and birth weight comparison of pregnant women in two intervention and control groups

\begin{tabular}{|lllll|}
\hline group & \multicolumn{2}{c|}{ control } & \multicolumn{3}{c|}{ intervention } \\
\cline { 2 - 5 } & count & percent & count & percent \\
\hline With Low birth weight & 63 & $19 \%$ & 38 & $12 \%$ \\
\hline Without low birth weight & 326 & $81 \%$ & 336 & $88 \%$ \\
\hline Total & 389 & $100 \%$ & 374 & $100 \%$ \\
\hline$X^{2}$ & $\mathrm{P}=0.03$ & & \\
\hline
\end{tabular}

Kaplan-Meier plot showed the lowest birth weight in the control group was 1800 grams and in the intervention group 2000 grams, and the low TFAs diet may be could increase the birth weight of the baby in the intervention group of 200 grams. $95 \%$ of newborns weighing less than 2500 grams in the control 
group had a variance of 1800-2100 grams, while 95 percent of newborns weighing less than 2500 grams in the intervention group weighed 2,200-2,000 grams (Fig. 2).

\section{Discussion}

In this study, we assessed the effect of dietary pattern with $<1 \%$ TFAs content intake during pregnancy with LBW risk. We found the negative effect of TFAs intake during pregnancy baby's birth weight. In this study the risk of LBW in intervention group decreased about $50 \%$. The incidence of LBW in intervention group was $12 \%$ vs. $19 \%$ in control group.

Few cohort and case- control studies have addressed the association between maternal TFAs intake and birth weight $(12,14-16)$. In none of these studies significant associations were reported, Possible interpretation include that we recommended individual diet design with TFAs content $\leq 1 \%$ for intervention group. It's worth mentioning that the control group also had individualized diet without focusing on TFAs content. Therefore, the effect of this intervention may exclusively explain by TFAs content. Another cause of difference possibly by lack maternal samples $\leq 600$. Study design may also be responsible for the differences in results.

Our findings are similar to studies in Amsterdam Born Children and their Development cohort, where they observed the association between higher levels of TFAs and reduced birth weight $(8,19)$. Similarly, other study in Maastricht Essential Fatty Acid Birth cohort. Also report a negative association between higher TFAs levels during pregnancy and decreased birth weight (20). In the current study, TFAs intake in intervention group was reduced and replaced by monounsaturated fatty acids (MUFAs) and polyunsaturated fatty acids (PUFAs) to meet daily energy requirement. Several mechanisms for a biological effect of the MUFAs and PUFAs on LBW risk may explain the observed association $(21,22)$. A study done on south Indian subject's reports the relationship between the lower intake of MUFA and PUFA during the third trimester of pregnancy and higher risk of delivering LBW babies (23). The third trimester of pregnancy greatest consumption of MUFA and PUFA done by the fetus (24). MUFA and PUFA are known to enhance membrane fluidity and raise flow mediated vasodilation, by that enhancing the membrane receptivity for various biologically active ligands. This may further lead to reduction in the blood viscosity and increase in the placental blood flow, by that enhancing fetal growth (25). Thus, the lower levels of MUFA and PUFA might reflect the mother's inadequacy to equip sufficient amounts of MUFA and PUFA for best fetal development.

There could be several possible mechanisms leading to changed levels of MUFA and PUFA in mothers delivering LBW babies as compared with mothers delivering normal birth weight babies: 1 ) it is well known that enzymes like desaturases synthesize the MUFA and PUFA from their critical shorter chain precursors (26). Thus, any alteration in the levels of these enzymes can affect the levels of fatty acids in the mother's circulation. 2) There may be genetic variations from the single nucleotide polymorphism of the FADS1 and FADS2, which may affect the maternal plasma and erythrocyte phospholipid levels of 
MUFA and PUFA during pregnancy $(27,3)$. Our earlier study in normotensive pregnancy reports a negative association between maternal homocysteine and maternal MUFA and PUFA levels at the time of delivery (27). It is therefore likely that the levels of maternal micronutrients like folic acid and vitamin B12 may also affect the levels of maternal MUFA and PUFA.

The strengths of the present study were as follows: individualized dietary pattern with difference in TFAs content ( $\leq 1 \%$ in intervention group) for both groups during the first trimester of pregnancy $(<7$ weeks) and assessed by $24 \mathrm{~h}$-recall questionnaire in every trimester. Additionally, we omitted other maternal risk factors that have been previously shown to be important for LBW. Our sample size was large enough to detect true effect of TFAs intake on risk of LBW. No previous study from Iran has investigated the effect of TFAs intake on risk of LBW.

A number of limitations of the study should be considered. First, if we took blood sample for assess serum level TFAs, it's better and we had sufficient power to true assess TFAs. Another limitation of our study is the narrow intake range for industrial TFAs in this population. This situation made it impossible to difference from our data whether TFAs intake truly is unrelated to LBW or whether it is related to this condition but only at intake levels that could not be observed in our study. To resolve this question further research is necessary in populations that remain exposed to large amounts of industrial TFAs in their food supply. Answering this question has major public health concerns.

\section{Conclusion}

Low TFAs intake can facilitate the control delivering babies with weight $<2500$ grams. Management of maternal nutrition with focused on TFAs content should be included in routine prenatal care, to facilitate interventions and guidance regarding maternal nutrition, with the goal of reducing the incidence of LBW. Further interventional studies are needed to confirm these results.

\section{Abbreviations}

TFAs: trans fatty acids

LBW: low birth weight

BMI: Body mass index

FCT: food composition table

Standard deviation (SD)

MUFAs: monounsaturated fatty acids

PUFAs: polyunsaturated fatty acids 


\section{Declarations}

Acknowledgments: We appreciate the cooperation of the Research Deputy of the university, The Head OF SBMU Research Institute for Endocrine Science and all study participants

Funding: This research is funded by Vice Chancellery of Research and Technology of shahid beheshti University of Medical Sciences. The funder has no role in the design and conduct of the study including collection, analysis, and interpretation of data, in writing of the protocol and decision to submit the manuscript for publication.

Ethics approval and consent to participate: The research project has received the confirmation of the Institution Ethics Committee (shahid beheshti University of Medical Sciences) with the number No. IR.SBMU.ries.Rec.1394.92. the consent form of our patients was taken and is available.

Consent for publication: Not applicable.

Competing interests: The authors declare that they have no competing interests.

Availability of data and material: Data on the main outcomes will be available.

Author's contribution: MS and SHA and PM participated in the conception, design of the study and implementation of research project. SHA and GA performed the statistical analysis. SHA and PM draft the manuscript. All authors read and approved the final manuscript.

\section{References}

1. Mclntire DD, Bloom SL, Casey BM, Leveno KJ. Birth weight in relation to morbidity and mortality among newborn infants. The New England journal of medicine. 1999;340(16):1234-8. Epub $1999 / 04 / 22$.

2. Black RE, Victora CG, Walker SP, Bhutta ZA, Christian P, de Onis M, et al. Maternal and child undernutrition and overweight in low-income and middle-income countries. Lancet. 2013;382(9890):427-51. Epub 2013/06/12.

3. Victora CG, Adair L, Fall C, Hallal PC, Martorell R, Richter L, et al. Maternal and child undernutrition: consequences for adult health and human capital. Lancet. 2008;371(9609):340-57. Epub 2008/01/22.

4. Organization WH. Global targets 2025 to improve maternal, infant and young child nutrition. 2013; Available from: nutrition/topics/nutrition_globaltargets2025/en/index.html

5. Delgado-Rodriguez M, Perez-Iglesias R, Gomez-Olmedo M, Bueno-Cavanillas A, Galvez-Vargas R. Risk factors for low birth weight: results from a case-control study in southern Spain. American journal of physical anthropology. 1998;105(4):419-24. Epub 1998/05/19.

6. Jackson AA, Bhutta ZA, Lumbiganon P. Nutrition as a preventative strategy against adverse pregnancy outcomes. Introduction. The Journal of nutrition. 2003;133(5 Suppl 2):1589S-91S. Epub 
2003/05/06.

7. Gluckman P HM. The fetal matrix. Evolution, development and disease. Cambridge, United Kingdom: Cambridge University Press; 2005.

8. van Eijsden M, Hornstra G, van der Wal MF, Vrijkotte TG, Bonsel GJ. Maternal n-3, n-6, and trans fatty acid profile early in pregnancy and term birth weight: a prospective cohort study. The American journal of clinical nutrition. 2008;87(4):887-95. Epub 2008/04/11.

9. Ghassemi H, Harrison G, Mohammad K. An accelerated nutrition transition in Iran. Public health nutrition. 2002;5(1A):149-55. Epub 2002/05/25.

10. Mozaffarian D, Katan MB, Ascherio A, Stampfer MJ, Willett WC. Trans fatty acids and cardiovascular disease. The New England journal of medicine. 2006;354(15):1601-13. Epub 2006/04/14.

11. Uauy R, Calderon F, Mena P. Essential fatty acids in somatic growth and brain development. World review of nutrition and dietetics. 2001;89:134-60. Epub 2001/09/04.

12. Olsen SF, Hansen HS, Secher NJ, Jensen B, Sandstrom B. Gestation length and birth weight in relation to intake of marine n-3 fatty acids. The British journal of nutrition. 1995;73(3):397-404. Epub 1995/03/01.

13. Lucas M, Dewailly E, Muckle G, Ayotte P, Bruneau S, Gingras S, et al. Gestational age and birth weight in relation to n-3 fatty acids among Inuit (Canada). Lipids. 2004;39(7):617-26. Epub 2004/12/14.

14. Grandjean P, Bjerve KS, Weihe P, Steuerwald U. Birthweight in a fishing community: significance of essential fatty acids and marine food contaminants. International journal of epidemiology. 2001;30(6):1272-8. Epub 2002/02/01.

15. Rump P, Mensink RP, Kester AD, Hornstra G. Essential fatty acid composition of plasma phospholipids and birth weight: a study in term neonates. The American journal of clinical nutrition. 2001;73(4):797-806. Epub 2001/03/29.

16. Elias SL, Innis SM. Infant plasma trans, n-6, and n-3 fatty acids and conjugated linoleic acids are related to maternal plasma fatty acids, length of gestation, and birth weight and length. The American journal of clinical nutrition. 2001;73(4):807-14. Epub 2001/03/29.

17. Makrides M, Duley L, Olsen SF. Marine oil, and other prostaglandin precursor, supplementation for pregnancy uncomplicated by pre-eclampsia or intrauterine growth restriction. The Cochrane database of systematic reviews. 2006(3):CD003402. Epub 2006/07/21.

18. Szajewska H, Horvath A, Koletzko B. Effect of n-3 long-chain polyunsaturated fatty acid supplementation of women with low-risk pregnancies on pregnancy outcomes and growth measures at birth: a meta-analysis of randomized controlled trials. The American journal of clinical nutrition. 2006;83(6):1337-44. Epub 2006/06/10.

19. Mehendale S, Kilari A, Dangat K, Taralekar V, Mahadik S, Joshi S. Fatty acids, antioxidants, and oxidativestress in pre-eclampsia. Int J Gynaecol Obstet 2008; 100: 234-238. PMID: 17977540

20. Dirix C, Kester AD, Hornstra G. Associations between neonatal birth dimensions and maternal essentialand trans fatty acid contents during pregnancy and at delivery. Br J Nutr. 2009; 101: 399407. doi:10.1017/S0007114508006740 PMID: 18613984 
21. Olsen SF, Østerdal ML, Salvig JD, Weber T, Tabor A. Duration of pregnancy in relation to fish oil supplementationand habitual fish intake: a randomized clinical trial with fish oil. Eur J Clin Nutr. 2007; 61:976-985. PMID: 17299499

22. Smuts CM, Borod E, Peeples JM, Carlson SE. High-DHA eggs: feasibility as a means to enhance circulatingDHA in mother and infant. Lipids. 2003; 38: 407-414. PMID: 12848286

23. Muthayya S, Dwarkanath P, Thomas T, Ramprakash S, Mehra R, Mhaskar A, et al. The effect of fishand omega-3 LCPUFA intake on low birth weight in Indian pregnant women. Eur J Clin Nutr. 2009; 63:340-346. PMID: 17957193

24. Innis SM. Metabolic programming of long-term outcomes due to fatty acid nutrition in early life. MaternChild Nutr. 2011; 7: 112-123.

25. Calder PC. Fatty acids and inflammation: the cutting edge between food and pharma. Eur Pharmacol.2011; 668: S50-S58. doi: 10.1016/j.ejphar.2011.05.085 PMID: 21816146

26. Smuts CM, Borod E, Peeples JM, Carlson SE. High-DHA eggs: feasibility as a means to enhance circulatingDHA in mother and infant. Lipids. 2003; 38: 407-414. PMID: 12848286

27. Xie L, Innis SM. Genetic variants of the FADS1 FADS2 gene cluster are associated with altered (n6)and (n-3) essential fatty acids in plasma and erythrocyte phospholipids in women during pregnancyand in breast milk during lactation. J Nutr. 2008; 138: 2222-2228. doi:

10.3945/jn.108.096156 PMID:18936223

\section{Figures}




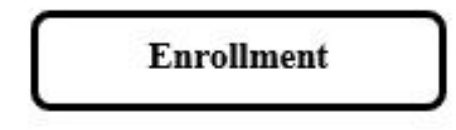

Pregnant women with eligible criteria $(\mathrm{n}=1016)$
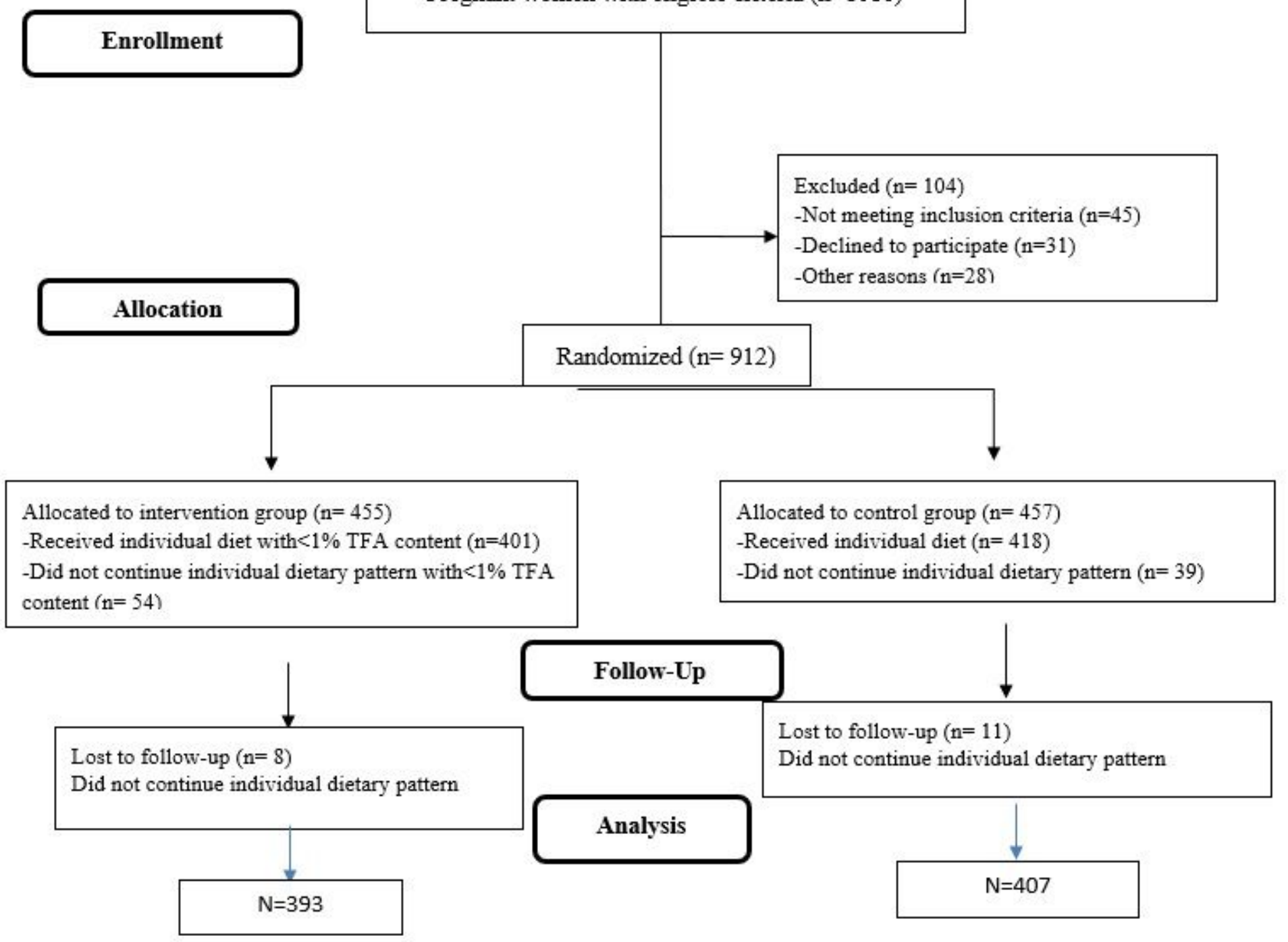

Figure 1

Consort Flow Chart 


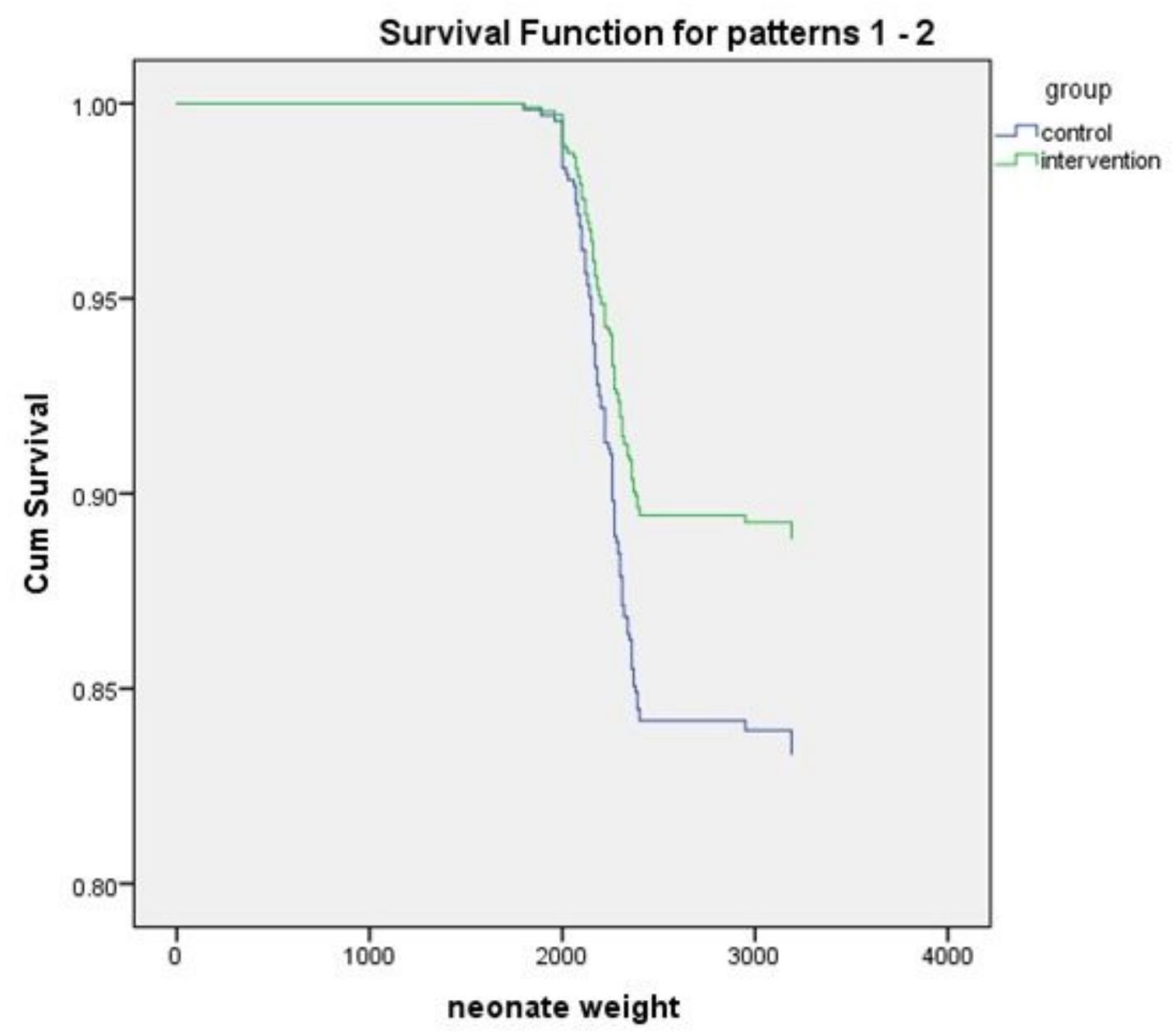

Figure 2

Kaplan-Meier plots for LBW in two intervention and control groups.

\section{Supplementary Files}

This is a list of supplementary files associated with this preprint. Click to download.

- CONSORT2010Checklist.doc 